\title{
Mechanisms of prism adaptation in normal monkeys
}

\author{
Joseph Bossom I \\ NATIONAL INSTITUTE OF MENTAL HEALTH, BETHESDA
}

\begin{abstract}
Ophthalmic prisms placed over the eyes of monkeys displace the retinal image and induce systematic misreaching. The rate at which accurate reaching is recovered during the prism exposure depends upon the type of information $\mathrm{S}$ obtains. It is most rapid when $\mathrm{S}$ can see his reaching errors and apparently displaced body and moves his head while wearing the prisms. Significant adaptation, although less marked, also occurs if $\mathrm{S}$ is permitted merely to move his head. It does not occur if the head is immobilized during the prism exposure.

\section{Problem}

Prism-wearing Ss may recover reaching accuracy in a single trial when they observe their arm in transit to the target. Under such direct visual control the arm moves first toward the apparent location of the image but during the course of this movement its trajectory is corrected as the discrepancy between its direction and the target's seen position is detected. By contrast, when the arm movement is obscured from view, recovery of accuracy occurs gradually during prolonged prism exposure rather than in a single trial.

This gradual reduction of misreaching has been extensively studied in man under a variety of test and exposure conditions. In some studies (Wooster, 1923) where stimulus, response, and reward contingencies were inherent in the procedures the process by which accurate reaching was re-acquired may be described in terms of traditional learning theories. Other studies (Held \& Bossom, 1961) which were designed to eliminate these contingencies found that prism adaptation did
\end{abstract}

not occur unless $\mathrm{S}$ obtained information in the form of changes in visual stimulation causally related to selfinitiated body movement. It is of major interest to understand the neural mechanism mediating this form of adaptation. Since neural mechanisms may be explored more suitably in monkey than in man, methods have been developed for studying this phenomenon in monkeys. The present report describes these methods and a preliminary study designed to determine whether monkeys will in fact adapt to prism-wearing on the basis of information provided by movement produced changes in visual stimulation.

\section{Proeedure}

Ss were six Macaca mulatta who were maintained and tested in primate chairs. The chairs were modified to receive either of two presentation shelves which were used to test reaching accuracy (Fig. 1). S could obtain a piece of food, usually a peanut, which had been placed on the far ledge of the shelf by reaching forward, up and around the ledge. In so doing his hand crossed a cm ruler. The distance between the point intersected by the radial surface of his hand and the food was the measure of reaching error.

The underside of both shelves was opaqued to prevent $\mathrm{S}$ from seeing either his arm or his body during the reaching tests. Shelf No. 1 permitted $\mathrm{S}$ to view his fingers through transparent plastic as they came into position alongside the target. Shelf No. 2 which was completely opaque, prevented $\mathrm{S}$ from seeing his fingers in that the food appeared briefly, framed in a small aperture which was covered by a shutter as soon as $\mathrm{S}$ initiated his reaching movement. When Shelf No. 2 was used several food rewards were placed on the far ledge so that $S$ was rewarded for all reaching trials regardless of their accuracy although he did not necessarily obtain the same peanut he had seen.

Prisms placed before S's eyes during the exposure period were held in place by a form-fitted helmet made from thermoplastic neoprene (Dupont H. C.). The 20 diopter binocular ophthalmic prisms which were used (A. O. No. 1815) were aligned and provided a visual

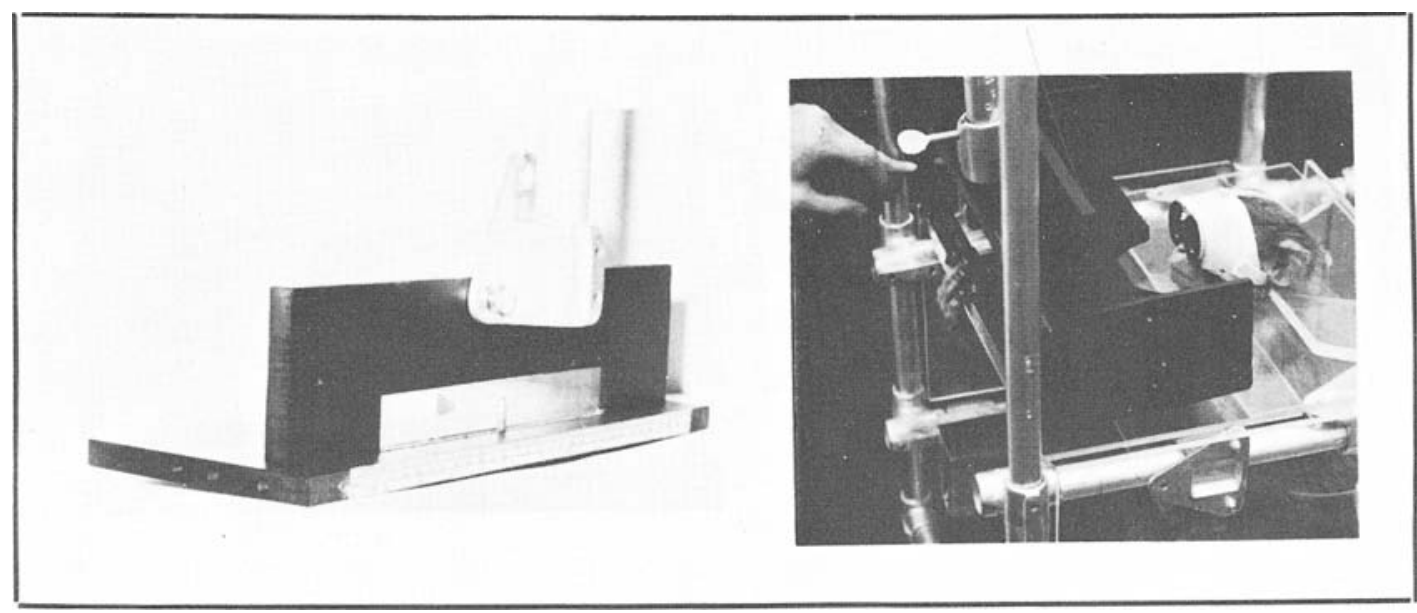

Fig. 1. Modified primate module with the two presentation shelves. The shelf on the left permits $\mathrm{S}$ to view his reaching errors. The shelf shown on the module does not. 


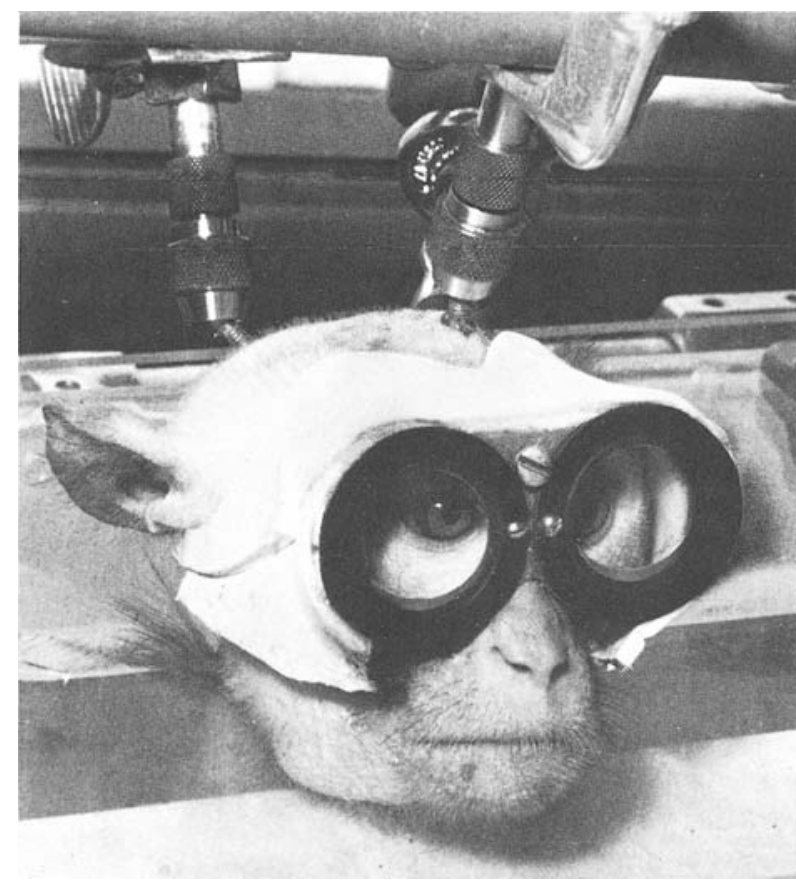

Fig. 2. To immobilize S's head, three bolts were affixed into the skull and secured to the primate chair. The internally threaded ball joints shown here (machinist's center finders) were used to prevent skull shear during this procedure.

field subtending $60^{\circ}$ displaced laterally toward the prism edge by approximately $11.2^{\mathrm{O}}$.

Three conditions, each differing in the amount and type of information provided to the $\mathrm{S}$ were contrasted. In the first condition $\mathrm{S}$ was permitted to see his reaching errors during testing and, during the prism-exposure period, allowed to view his apparently displaced body through the collar of the transparent primate chair. In the second condition the second shelf (opaque) was employed so that $\mathrm{S}$ could not obtain information about his reaching errors during the testing. Furthermore, an opaque collar was added to the primate chair during the prism-exposure which prevented $\mathrm{S}$ from seeing his body during that period. $\mathrm{S}$ was permitted to move his head during both conditions. The third condition was identical to the second except that S's head was immobilized during the entire procedure in the manner shown in Fig. 2.

The general procedure consisted of a test-exposure-retest sequence. Accuracy of reaching was tested immediately before and after the prisms were placed over S's eyes and following $7 \mathrm{hr}$. of exposure, before and after their removal. Ss were tested twice in each condition and on each replication the prisms were rotated $180^{\circ}$ to control for day-to-day summative effects which have been described elsewhere (Wooster, 1923; Held \& Bossom, 1961). Ss were tested in the three conditions in a varied order.

\section{Hesults and Discussion}

There was a significant overall difference between the three conditions $(\mathrm{F}=18.4 ; \mathrm{df}=2 / 18 ; \mathrm{p}<.001)$. In condition one $86 \%$ of the prism-induced misreaching was corrected by the end of the 7-hr. exposure period and in condition two, $44 \%$ was overcome $(p<.01)$. The amount of adaptation in condition three was only $12 \%$, which is not significantly greater then zero. The amount of adaptation in the first condition was significantly greater than in the second condition $(p<.05)$ and in the third condition $(p<.001)$. The amount of adaptation in the second was significantly greater than that obtained in the third condition $(p<.05)$.

In a previously reported study of visuomotor prism adaptation in monkey, (Bossom \& Hamilton, 1963) Ss were permitted to observe their reaching errors and their bodies. The purpose of the present study was to contrast adaptation under such conditions with that obtained using conditions which provide Ss with less information. The results demonstrate that monkeys will correct prism-induced misreaching even though they do not see their bodies during the exposure or their reaching errors during testing. To this extent these data parallel that previously reported for man (Held \& Bossom, 1961).

There is no published report of prism adaptation in man under conditions comparable to those employed in condition three. Although prism adaptation had been reported in human Ss who have had their heads held in a bite board during the exposure period, the conditions and results of these studies suggest that another process is involved. These Ss were permitted to view either their body or arm movement through the prisms but the adaptation which rapidly occurs was reflected only in the localizing movements made with the limbs that were actually viewed (Hein \& Held, 1958, 1960; Wallach et al., 1963). By contrast, adaptation which occurs when head movements are performed during the prism-exposure is a more general effect which transfers to different limbs, (Hamilton, 1964; Bossom \& Held, 1959).

On the basis of the similarity between these results with monkeys and those obtained under analagous conditions with man, it would seem legitimate to use monkeys in an analysis of the neural basis of visuomotor prism adaptation. Such studies, designed to further investigate the neural process involved in adaptation and the brain structures which subserve it are now in progress.

\section{References}

BOSSOM, J., \& HELD, R. Transfer of error correction in adaptation to prisms. Amer. Psychologist, 1959, 14, 436. (Abstract)

BOSSOM, J., \& HAMILTON, C. R. Interocular transfer of prism altered coordinations in split-brain monkeys. J.comp. physiol. Psychol., 1963, 56, 769-774.

HAMILTON, C. R. Intermanual transfer of prism adaptation. Amer. J. Psychol., 1964, 77, 457-462.

HEIN, A., \& HELD, R. Minimal conditions for complete adaptation to prismatic displacement of vision. Paper read at Eastern Psychol. Ass., Philadelphia, April, 1958.

HEIN, A., \& HELD, R. Transfer between motor systems of adaptation to prismatic displacement of vision. Paper read at Eastern Psychol. Ass., New York City, April, 1960.

HELD, R., \& BOSSOM, J. Neonatal deprivation and adult rearrangement: Complimentary techniques for analyzing plastic sensorimotor coordinations. J.comp. physiol. Psychol., 1961, 54, 33-47.

WALLACH, H., KRAVITZ, J. H., \& LINDAUER, J. A passive condition for rapid adaptation to displaced visual direction. Amer. J. Psychol., 1963, 76, 568-578.

WOOSTER, M. Certain factors in the development of a new spatial coordination. Psychol. Monogr., 1923, 32. 146.

\section{Note}

1. The author is indebted to his colleagues, H. E. Rosvold, M. Mishkin and J. Semmes for their many helpful discussions and criticisms. 